\title{
Understanding the Interdependences Among Performance Indicators in the Domain of Industrial Services
}

\author{
Ingo Lange ${ }^{1}$, Oliver Schneider ${ }^{1}$, Matthias Schnetzler ${ }^{1}$ and Lee Jones ${ }^{2}$ \\ 1 ETH Zurich, Center for Enterprise Sciences (BWI), 8092 Zurich, \\ Switzerland, ilange@ethz.ch, oschneider@ethz.ch, mschnetzler@ethz.ch \\ WWW home page: http://www.lim.ethz.ch \\ 2 Ventana Systems UK Ltd., CH43 5RD Oxton Merseyside, \\ United Kingdom, lee.jones@ventanasystems.co.uk, \\ WWW home page: http://www.ventanasystems.co.uk
}

\begin{abstract}
Within the context of the EU-Project InCoCo- 'S', one of the key aims is to standardize integrative industrial service processes in order to facilitate transparency on service operation performance and the resulting customer benefit. Therefore the Service Performance Measurement System (SPMS) has been developed in order to quantify both the efficiency and effectiveness of industrial service operation activities and to support the measurement of customers` benefit through industrial service activities. But performance indicators are only a measurable expression of the underlying system performance, a system which is ordinarily complex in nature. It follows, therefore, that it would be beneficial to understand the interdependences between performance indicators in order to better utilize them in evaluating the options for improvements in system performance and the monitoring of an often complex system. Based on a comprehensive literature review and making best use of the tools and expertise available to the InCoCo-S consortium, a process to develop an understanding of the interdependences between performance indicators was created and executed. The results provide both the service provider and the manufacturing customer with an insight into those performance indicators to be targeted for improvement actions and those better suited to monitoring.
\end{abstract}

\section{Keywords}

Performance indicators, service performance measurement system, industrial service operations, interdependences among performance indicators,

interdependency matrix 


\section{Introduction}

Increasing customer requirements, ever faster changing environments and increased competition are often mentioned as important, general business trends. The packaging machine industry is one example where these trends, which pressure companies into a continuous improvement cycle, can be observed. One challenge is to improve the level of satisfaction and quality of co-operation at the service interface by integrating service providers in the customers processes [1].

Based on intensive literature research and the results of a survey, the assumption was validated that there exists no standard performance measurement system addressing the special requirements for industrial services so far, but there is an unsatisfied business need for that [2]. After analyzing 1,352 papers published in 546 different journals, Andy Neely [3] stated in 2005, that an academic professionalism in the field of performance measurement has not yet occurred. Only since the late $1990 \mathrm{~s}$, an increasing shift in the performance measurement literature to more theoretical and methodological pieces occurred, which is an indicator for academic professionalism [3]. Basically, a performance measurement system`s (PMS) purpose is to measure process activities which are linked together and characterized by complexity and high interdependency. Based on the researched literature there are various PMS available, but only a few authors have given consideration to the relations between performance measures. However, in literature this area has not been adapted to the special needs of service operations performance. Due to this fact, the objective of the paper is to show the interrelations in a qualitative way. For this purpose, potential methods have been analyzed. The paper presents and makes use of Vester's paper machine [4], which is basically an influence matrix for identifying and evaluating a system's critical variables. Based on the results, it will be possible to cluster important performance drivers and to support companies in the selection of relevant PIs, especially in the packaging business.

\subsection{Methodology}

The research methodology incorporates the principles of action research, which consist of involvement of industrial partners through workshops and a structured research process. Based on literature review (desk research) and workshops, relevant PIs have been identified and the Service Performance Measurement System (SPMS) was developed. The structure of the system and the PIs were validated in industrial settings by means of a proof of concept.

The System Dynamics (SD) software tool, Vensim ${ }^{\circledR}$, has been used in the development of correlation between previously isolated PIs. Vensim has powerful causal analysis and sensitivity tools including Causal Tracing ${ }^{\mathrm{TM}}$ using causes trees. The Causal Tracing ${ }^{T M}$ capabilities of the simulation software have been used to create causal trees for qualitative analysis of the connectivity between service processes and the hierarchy of the PIs. For the investigation of the interdependences among the PIs of the SPMS, potential methods have been reviewed by literature research. Ensuring practical relevance, the selected conceptual tool (Vester's paper 
machine) for showing influences among the considered PIs has been put into practice by using industry partners experiences in the domain of industrial service business.

\subsection{Service Performance Measurement System (SPMS)}

Industrial service operations are usually a result of the interaction between customers (OEM) and the service provider, including the service staff, production data exchange, service equipment, service environment and facilities. Figure 1 illustrates an overview of the SPMS structure and presents the two dimensions Service Perception and Service Encounter Interface.
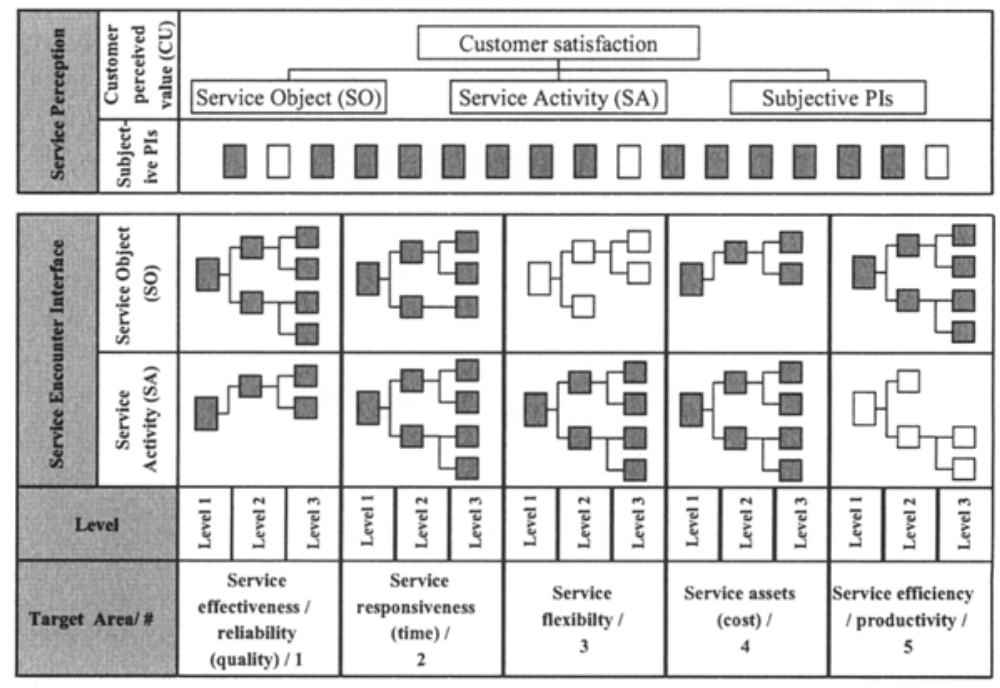

Fig. 1. The structure of the SPMS

The basic idea of the Service Perception is to have a dimension quantifying the gap between actual service operation performance based on objective measures and the perceived service operation performance from the customers' perspective. The dimension Service Encounter Interface provides a comprehensive set of approx. 120 PIs structured by different target areas to firstly measure the service providers internal service operation performance and secondly to measure the performance of the processes at the interface with the customer which directly affect the performance of the service operation. In reference to the SCOR model [5], the differentiation in overall goals (target areas) helps in selecting specific PIs according to the companies strategic goals. As an enhancement of existing PMS the Service Encounter Interface is divided into the sections Service Activity (SA) and Service Object (SO): Service activity (SA) relates to all process steps to be taken to fulfil the specified level of service; e.g., alignment of required production capacities and planned maintenance service or productivity consulting. The SA view is measuring 
how efficient and reliable the service offerings like maintenance, modernization, and trainings are offered to the customer [6]. Service object (SO) refers basically to the element (process and/or object) in the customers' manufacturing supply chain that is being serviced. In reference to a physical asset this implies the resulting condition of the service object (e.g. machine, software) required to guarantee a specified level of service object performance; e.g. increased availability of a packaging machine [6].

Following this structure, each target area is providing a hierarchical tree of generic PIs on level 1-3. In addition, the performance indicators facilitating the measurement of industrial service operations are linked to reference service processes, the InCoCo-S Reference Model (IRM). In the paper, the focus is on the 38 Level 2 PIs which are representing the service operation performance in accordance to Level 2 service operation processes in the IRM.

\section{Research background}

In this section the focus is on the selection of available methods and tools which might be useful for analyzing interdependences between performance measures in the briefly introduced SPMS. The etymological meaning of interdependence (lat.) is "mutual dependence". Interdependence contains in contrast to dependence a retrospective among all involved objects. With a brief introduction into the world of systems the theoretical background of interdependences is outlined.

\subsection{Systems Thinking and the Interdependency Matrix (IM)}

Ulrich [7] defines a system as a whole consisting of elements. In this context "whole" denotes that the system is clearly distinguishable from surrounding things and even the inside is heterogeneous. Vester adds to this very generic definition another essential attribute of systems: Beside the fact that systems consist of distinguishable parts, it is important to mention that these parts are linked to each other in a certain structure [4]. The nature of these relations is, however, not further explained. In reality it could be flows of material, information, or energy as well as cause-effect relations. The extension of Vester also fits in the understanding of systems as sets of elements which are linked to each other. A better knowledge and understanding of interdependences is not only desired in the field of performance measurement. In respect of a more effective analysis of complex systems, a consideration of interdependences is necessary. The common way of analyzing a system focuses on the structure and the isolated system elements. By this means the gained information contains nothing about how the system elements interact with each other.

As a result of the literature research, the Interdependency Matrix (IM) was selected as a very simple method for analyzing interdependences among performance measures and is therefore a suitable method for the presented purpose. The IM is based on the so-called paper computer according to Frederic Vester [4], Ninck [8] and Ulrich [7], and helps identifying and evaluating a system's critical variables. The matrix allows the calculation of three approximate measures (called 
"influence indices") for the extent to which any variable: (a) influences other variables; (b) is itself influenced by them; and (c) is a critical leverage point for intervening into the system. Therefore the $I M$ is useful to depict the interdependences among the Pls of the SPMS. The two-dimensional matrix contains all performance indicators arranged vertically and horizontally, with the matrix entries indicating the strength of influence of the PI on the vertical axis on those PIs arranged along the horizontal. In the IM, a value of "1" or " 2 " means that the PI in the corresponding row has a medium or strong influence on the PI of the corresponding column, while a value of " 0 " indicates that there is no significant influence in general. For the application of the method to the investigation of interdependences among PIs, the IM is defined as follows:

- IM nxn is a $\mathrm{n} \times \mathrm{n}$-Matrix with $\mathrm{n}=$ number of PIs

- for each element mij $\in \mathrm{IM}$ : mij is the weighted influence of PIi on PIj with $\mathrm{i}, \mathrm{j}=1 \ldots \mathrm{n}$ and $\mathrm{m} \in\{0,1,2\}$

The objective of the IM is to assess the characteristic of each PI in order to better understand its role and use in the framework of the SPMS. In order to facilitate this, the following figures are calculated [8]:

- Active sum of PIi: $\mathbf{A S i}=\sum \mathrm{mij}$ for $\mathrm{j}=1 \ldots \mathrm{n}$

ASi indicates the degree of influence of a certain PIi on other PIs. The higher the AS, the higher the influence on other PIs.

- Passive sum of PIj: PSj $=\sum$ mij for $i=1 \ldots n$

$\mathrm{PSj}$ indicates the degree of how a certain PIj is influenced by other PIs. The higher the PS, the higher the PI is influenced by other PIs.

- $\quad$ Product of PIi: $\mathbf{P i}=$ ASi $\cdot$ PSi

$\mathrm{Pi}$ indicates the intensity of cross-linking of a certain PIi. The higher $\mathrm{P}$, the more a certain PI is cross-linked with other PIs.

- Quotient of Pli: Qi = ASi / PSi

Qi indicates the intensity of activity of a certain Pli. A low $Q(Q<1)$ means that a certain PI is more influenced by other PIs than influencing other PIs.

\begin{tabular}{|c|c|c|c|c|c|c|}
\hline $\begin{array}{l}\text { Influence of } \downarrow \\
\text { on } \rightarrow\end{array}$ & PI1 & $\mathrm{PI} 2$ & PI3 & PIn & AS & $\mathbf{P}$ \\
\hline PI1 & & 1 & 1 & 0 & 2 & 6 \\
\hline $\mathrm{Pl} 2$ & 1 & 48 & 1 & 1 & 3 & 15 \\
\hline $\mathrm{PI} 3$ & 0 & 2 & 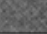 & 2 & 4 & 8 \\
\hline Pln & 2 & 2 & 0 & 02 & 4 & 12 \\
\hline PS & 3 & 5 & 2 & 3 & & \\
\hline $\mathbf{Q}$ & 0.7 & 0.6 & 2 & 0.6 & & \\
\hline
\end{tabular}

Fig. 2. Interdependency Matrix (IM) (example) 
Using the figures AS, PS, P, and Q, the results can be assessed and interpreted as follows $[7,8]$ :

- Active PIs with $Q>1$ are influencing other Pls to a high degree and are hardly influenced by other PIs.

- Passive PIs with $\mathbf{Q}<1$ are influenced by other PIs to a high degree and hardly influencing other PIs.

- Cross-linked PIs with $\mathbf{P}=$ high (e.g., $\mathrm{P}>0.5 \cdot \operatorname{Max}(\mathrm{Pi})$ with $\mathrm{i}=1 \ldots \mathrm{n})$ are highly connected to other PIs and are involved into many cause-effect relationships (interdependences). Their influence is high and they are influenced.

- Isolated PIs with $\mathbf{P}=$ low (e.g., $\mathrm{P}<0.5 \cdot \mathrm{Max}(\mathrm{Pi})$ with $\mathrm{i}=1 \ldots \mathrm{n}$ ) are hardly influencing other PIs and are not highly influenced.

The PIs can be positioned according to P and Q in an Interdependency Portfolio.

\subsection{Research approach}

The hierarchies of PIs developed in the SPMS were transferred to the Vensim software, in order to be able to exploit the causal tracing capabilities of the package. These were further combined with the IRM in order to present a complete causal picture of the relationship between processes, their performance indicators at level 3, and the hierarchy of PIs up to level 1 . To assist in the assessment of interdependence between Level 2 PIs, individual causal trees for the 38 Level 2 PIs were created, and the influences between these pairs of Level 2 PIs have been recorded with the Interdependency Matrices for different service clusters.

\section{$3 \quad$ Results}

This section details the results of the interdependency exercise for the packaging service area in the project. An analysis of the Interdependency Matrices in MS-Excel is presented and the section concludes with an overall interpretation of the results.

Of the 38 Level 2 Performance Indicators, 33 (87\%) were considered for the packaging service. Of these 33, 17 were active, 16 passive and $9(27 \%)$ were considered active and isolated with PIs 18 (Resource adaptability to modifications of the service object/ operation process) and 21 (Service object production/ operating flexibility) being the most notable (all within the target area service flexibility).

Based on the $P$ and $Q$ values, in Figure 3 the PIs are positioned in the Interdependency Portfolio (IP). The positioning of the PIs in the IP can be used to determine appropriate use of the PIs [7,8]. According to [9] the results are interpreted to develop improvement strategies:

- Active and isolated: Intervention, Controlling

Interventions here can have a huge impact on a few other PIs. Therefore, they are levers that can be used to influence a system in a targeted way. See 
e.g. PI 19 (Resource flexibility in service operations) in the IP.

- Active and cross-linked: Accelerators, selective interventions

Selective interventions here are crucial and may be used as accelerators of trends. There may be feedback loops that intensify the impact. See PI 4 (Service interaction reliability).

- Passive and isolated: Stabilizers, Monitoring

Since such PIs show influences with delays, they are stabilizers and should be used for long term monitoring. See PI 32 (Service interaction costs).

- Passive and cross-linked: Indicators, Monitoring

Such PIs should be primarily used as indicators for monitoring the status of a system on a mid or long term basis. See PI 8 (Service operating output quantity).

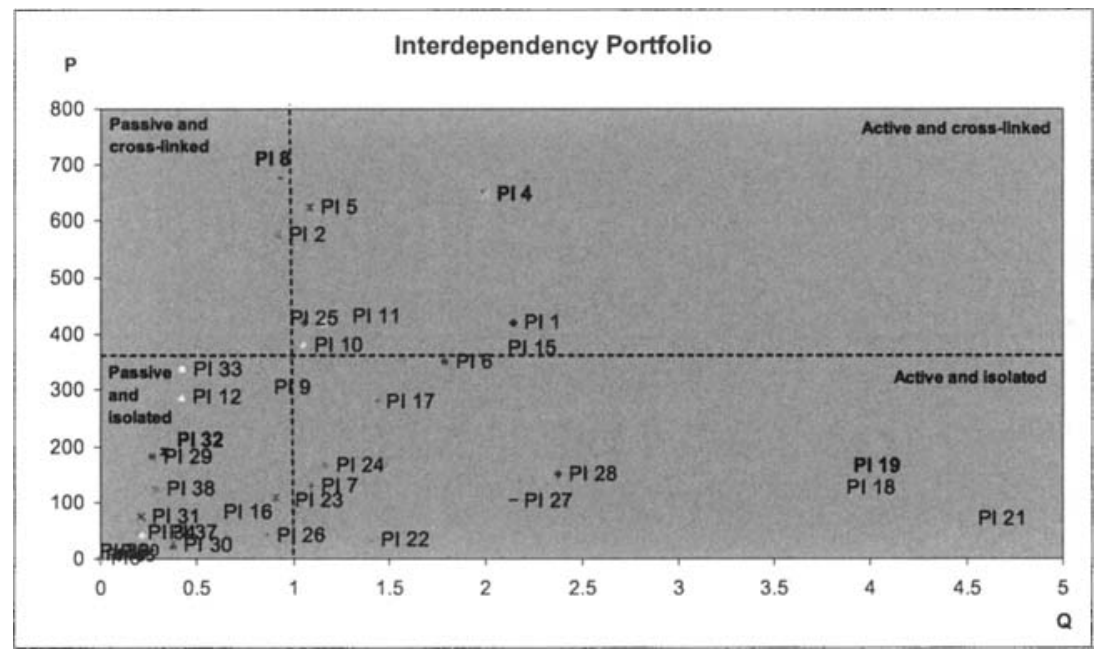

Fig. 3. Interdependency Portfolio for the Packaging Service

The IM which served as the basis for creating the IP contains information about all entries determined to be a strong influence (value=2). For example, service interaction reliability (PI 4 ) has a strong influence on service adapt cycle time (PI 22), service build cycle time (PI 23), service interaction cycle time (PI 24) and service operate cycle time (PI 25). The higher the interaction reliability in terms of availability and quality of shared information with customers and other service providers ( $3^{\text {rd }}$ party suppliers), the fewer communication loops are necessary to ensure a timely delivery of material and man power. Another interesting observation is the strong interrelation between service adaptability/flexibility and the ability to launch new services (PI1) and to perform existing services to a higher level of performance (PI7). This is due to the fact that, e.g. better Resource flexibility in service operations (PI 19) comprising higher education level, number of languages spoken and investments in personnel trainings result in advanced service operations performance. This connection expresses the importance of staff trainings for the 
ability to offer new services (e.g. taking over of the complete packaging process) and the efficient processing of regular services. In addition, PI 19 has a medium impact on almost every Level 2 PI across the different target areas (cost and reliability) highlighting the power of PI 19 (active and isolated) to influence the system in a targeted way.

\section{Conclusion and Outlook}

The methods used to elicit the interdependences between PIs in the Service Performance Measurement System (SPMS) have served to better understanding of the appropriate use of a certain PI and its role in a cross-linked system, as well as the development of service operation improvement strategies for service providers (where and how to intervene in order to improve process performance). The results enable the service provider and the client manufacturer to evaluate the potential impact of improvements in an indicator on other areas of their business and illustrate areas where great care should be taken to fully understand the cause-and-effect and feedback structures present in their business. In future research activities the result will have an impact on the development of a methodology for the individual assignment (selection) of PIs to various services.

\section{References}

1. Lange I, Schneider O, Larsson A, Minkus A (2006): Logistics controlling concept for benchmarking service delivery performance. In: Proceedings of the 11 th World Congress for TQM; December 4-6, 2006, Wellington, New Zealand

2. Osadsky, P.; Fischer, T.; Garg, A.; Lange, I.; Schaedlich, B.; Schneider, O.; Montorio, M.; Nitu, B.; Puetz, F. (2006): Innovation, Coordination and Collaboration in Service Driven Manufacturing Supply Chains (Brochure to EU-funded project InCoCo-'S', www.incoco.net)

3. Neely, A., (2005): The evolution of performance measurement research. In: International Journal of Operations \& Production Management, 12/2005, S. 1264-1277.

4. Vester, F., (1999): Neuland des Denkens: Vom technokratischen zum kybernetischen Zeitalter, 11. Aufl., München, 1999

5. Supply Chain Council (2006): Supply chain operations reference model SCOR Version 8.0. Pittsburgh: Supply Chain Council (http://www.supply-chain.org)

6. Lange, I.; Schnetzler, M.; Schneider, O.; Osadsky, P., (2007): Design of a Performance Measurement System. In: Proceedings of the 2nd International Conference on Changeable, Agile, Reconfigurable and Virtual Production (CARV), 22.-24. July 2007, Toronto

7. Ulrich, H.; Probst, J.B., (1988): Anleitung zum ganzheitlichen Denken und Handeln: Ein Brevier für Führungskräfte, Bern, Haupt, 1991

8. Ninck, A. et al., (2004): Systemik: vernetztes Denken in komplexen Situationen, 4. Aufl., Verlag Industrielle Organisation, Zürich, 2004

9. Schnetzler, M.; Sennheiser, A., (2003): Identification of performance improvement strategies in production networks. In: Cunningham, P. et al.: Building the knowledge economy - issues, applications, case studies. Amsterdam: IOS Press / Omsa, 2003, pp. 306-312 